\title{
PHYSICS OF SOCIAL EQUILIBRIUM
}

$\mathrm{T}$ HE paper read by Dr. R. Fürth, reader in theoretical physics in Birkbeck College, London, on August 15 at the Edinburgh meeting of the British Association under this title broke new ground, and the enterprise of the author is a welcome sign that the natural scientist is making even more strenuous endeavours than he has done in the past to apply the concepts he has developed to social problems. A large amount of the work which has been carried out in the 'natural' and 'social' worlds has always been of common interest to both, as, for example, the theories of evolution developed during the nineteenth century. Nothing but good can come from the sharing of ideas and co-operative endeavour, provided that there is a clear understanding that there are fundamental differences between, as it were, the 'climates' of the two worlds, and that what is useful and will prosper in one world will not necessarily survive in the other.

At the beginning of his paper, Dr. Fürth has underlined the dangers that beset us when this proviso is neglected. As he points out, the use of physical models for the understanding of social phenomena has often led to gross over-simplifications, and sometimes to disastrous misunderstandings. Exam. ples cited in the paper include the familiar analogies which are drawn between the concepts of 'forces', 'balances' and 'equilibrium', which refer to the properties of solid structures, and the behaviour of social communities. The model of a rigid body is, in fact, often used in popular literature to explain the processes of social change. Expressions such as 'the swing of the political pendulum' have crept into everyday language, and the result, as Dr. Fürth points out, is to give the ordinary citizen the erroneous belief that "present difficulties will in due course resolve themselves automatically by the working of some miraculous social mechanism".

Dr. Fürth is, of course, correct when he finds the distinction between mechanical machines and social communities in the voluntary working of the latter, and in the intelligent co-operation which exists between its parts. But he tends to over-state his case when he argues that the use of statistical techniques in the analysis of human behaviour may tend to predictions that are "completely wrong". It is perfectly just to point out that "the fate of the spinning ball is in no way influenced by the results of previous games", and to argue that predictions of social, as contrasted with natural, events are often invalidated by the mere fact that they have been communicated to the persons whose behaviour was the subject of the experiment. But in this case the statistician's 'other things' are not 'equal', and the validity of statistical techniques is left unimpaired. Indeed, the value of prediction in the social field often lies in the fact that processes of social change can be set in motion to avoid the occurrence of such phenomena as population decline that would otherwise take place.

Dr. Fürth's criticism of statistical techniques is, surely, only valid if the end-product of social science is accepted as the understanding of the very purposes of human life itself, and few social scientists would be presumptuous enough to maintain anything so outrageously ambitious. The main achievements of social scientists during the past generation have been to demonstrate that the extent to which human society is, in fact, 'voluntary' and human co-operation 'intelligent', is very much less than the intelligent Victorian believed or the common-sense man of to-day assumes. It is the unconscious influences that determine our everyday behaviour, and the undirected processes that shape the structure and development of human societies, to which we are turning our attention in increasing degree, and it is in that area of human experience that the methods of the natural sciences are most directly applicable. To what extent the unconscious can and should be made conscious, and the undirected brought under control, remains to be seen. But much (perhaps everything) that makes for human survival depends on it.

Dr. Fürth ends his paper with a plea for the application of statistical mechanics, the branch of theoretical physics which has been developed for the theoretical treatment of many physical phenomena, to the problems of social organization. In so far as the principal field of application, as Dr. Fürth points out, has been to the physics of systems or 'assemblies' of very large numbers of identical particles, there is a strong probability that social scientists will find in this branch of knowledge a valuable means for unravelling the very baffling problems which arise from the interaction between the individuals which compose a social group or community. But to argue more than this at the present time is highly misleading. To compare (as Dr. Fürth does) the behaviour of 'communities' of crystals of pure substances with that of human societies is surely to create the confusions and encourage the errors which he so rightly deplores at the beginning of his paper. To ascribe the political stability of the United Kingdom and of the British Commonwealth of Nations to "the soundness of their structures on the physical principles of strength of material bodies" is, at least, a gross over-simplification. The value of "statistical mechanics" for the social scientist must first be demonstrated by painstaking experiment in the factory working group or the housing estate neighbourhood before such generalizations are permissible.

T. S. SIMEY

\section{FIELD-WORK IN ZOOLOGY}

A

DISCUSSION on "Zoology at the Marine, Freshwater and Field Stations" was held in Section D (Zoology) of the British Association at Edinburgh on the morning of August 13. Mr. E. Ford, director of the Marine Station at Millport, opened the discussion by describing the development of marine stations in Great Britain and abroad. His own station at Millport had as its first home the Ark, originally a floating laboratory moored in a submerged quarry at Granton, Edinburgh. Whereas in former days the attitude was that of the general practitioner in the broad field of zoological inquiry, the present tendency is to think and work as specialists. Specialization not only canalizes aim and effort but also leads almost inevitably to specialized institutions. The majority of the stations in Great Britain were at first committed by constitution to study the life of fishes in the interests of British commercial fisheries. 